\title{
Resposta terapêutica e inflamatória de ratos com peritonite secundária submetidos ao uso tópico de ampicilina/sulbactam
}

Flávio Kreimer ${ }^{1}$,José Lamartine de Andrade Aguiar ${ }^{2}$, Célia M M B Castro $^{3}$,
Cláudio Moura Lacerda ${ }^{4}$, Tarcisio Reis $^{5}$, Fernando Lisboa Júnior $^{6}$

Kreimer F, Aguiar JLA, Castro CMMB, Lacerda CM, Reis T, Lisboa Júnior F. Resposta terapêutica e inflamatória de ratos com peritonite secundária submetidos ao uso tópico de ampicilina/sulbactam. Acta Cir Bras [serial on line] Available from: URL: htt:// www.scielo.br/acb.

RESUMO - Objetivos: A peritonite aguda representa uma importante causa de sepsis e óbito nas unidades de terapia intensiva e cirurgia. Classicamente o seu tratamento deve incluir: a administração sistêmica de antibióticos, a remoção mecânica dos contaminantes e a restauração da integridade gastrintestinal. A utilização de antibióticos diretamente na cavidade peritoneal é controversa. Estudo com o objetivo de avaliar o uso terapêutico, intraperitoneal da ampicilina associada ao sulbactam. Métodos: foram mensurados os níveis plasmáticos do óxido nítrico, bem como a contagem de eosinófilos, linfócitos, monócitos e neutrófilos no sangue e no lavado peritoneal, utilizando-se modelo de peritonite em ratos (ligadura-transfixação cecal). Vinte quatro ratos Wistar, machos, foram divididos em quatro grupos de seis animais, assim distribuídos: grupo A: método de indução de peritonite - soltura da ligadura + tratamento com soro fisiológico; grupo B: método de indução de peritonite + soltura da ligadura + tratamento com soro fisiológico acrescido de ampicilina / sulbactam; grupo C: método de indução de peritonite + soltura da ligadura-transfixação cecal; e grupo D: laparatomia para realização de lavado peritoneal mais coleta de sangue. A ligadura-transfixação do cecum permaneceu por 24 horas, antes do tratamento instaurado. Foi realizada uma relaparotomia nos 18 ratos com coleta de líquido de lavado peritoneal e sangue. Foram dosados os níveis plasmáticos de óxido nítrico e determinado o número de eosinófilos, linfócitos, monócitos e neutrófilos no sangue e no lavado peritoneal. Resultados: Não ocorreu diferença estatisticamente significante $(p>0,05)$ nos níveis de óxido nítrico, bem como no número de eosinófilos, linfócitos, monócitos e neutrófilos no sangue e no lavado peritoneal, entre os grupos. Conclusão: Neste estudo, concluiu-se que: a utilização de ampicilina associada a sulbactam por via intraperitoneal nos ratos com peritonite fecal: não modificou a sobrevida; não alterou os níveis plasmáticos de óxido nítrico; não alterou a contagem de eosinófilos, linfócitos, monócitos e neutrófilos tanto no sangue como no lavado peritoneal.

DESCRITORES: Peritonite. Antibióticos. Ratos.

\section{Introdução}

A peritonite é uma das causas mais freqüentes de sepsis e óbito nas unidades de terapia intensiva e cirurgia .

Na peritonite a sepse ocorre quando um foco infeccioso intraabdominal desencadeia uma resposta sistêmica. Esta resposta se caracteriza por ativação nos sistemas de cascata (complemento, coagulação, cininas, fibrinólise), células (endoteliais, leucócitos, monócitos, macrófagos e mastócitos) e liberação de mediadores (radicais livres de oxigênio, histamina, eicosanoides, fatores de coagulação e citocinas) ${ }^{2}$.

O óxido nítrico $(\mathrm{ON})$ é uma molécula filogeneticamente muito antiga com funções as mais diversas em fisiologia e patologias humanas . Em resposta sistêmica a peritonite bacteriana, o endotélio sintetiza o ON, que tem a função de relaxar a musculatura vascular e alterar o endotélio através da guanidina-monofosfato (GMP), que remove os íons de cálcio

intracelulares. O ON está elevado no plasma de pacientes em choque séptico ${ }^{4}$, e na luz dos vasos inibe a adesão de leucócitos e plaquetas. O ON produzido nos polimorfonucleares e macrófagos auxilia na destruição dos microorganismos ${ }^{5}$. Os leucócitos são as principais células efetoras da inflamação aguda. A resposta imune é mediada leucócitos polimorfonucleares e os macrófagos, células da resposta imune inata, enquanto os linfócitos, são células da resposta adaptativa. Uma vez amadurecidos, os macrófagos e os mastócitos residem nos tecidos do corpo, mas todas as outras células do sistema imunológico circulam no sangue. Os macrófagos e os neutrófilos possuem receptores de superfície que evoluíram para exercer o reconhecimento de muitos constituintes comuns de superfícies microbianas. As moléculas bacterianas que se ligam a tais receptores estimulam as células a fagocitarem bactérias e também induzem a

1 Mestre em Cirurgia, CCS- UFPE.

2 Prof. Adjunto da Base da Técnica Cirúrgica, CCS-UFPE.

3 Profa. Adjunta de Medicina Tropical, CCS-UFPE.

4 Prof.Titular de Cirurgia Abdominal da UPE e Prof. Adjunto de Cirurgia Abdominal, CCS-UFPE.

5 Aluno do Doutorado em Cirurgia, CCS-UFPE.

6 Residente de Cirurgia do Hospital Agamenon Magalhães. 
secreção de citocinas e de outros mediadores químicos pelos macrófagos .

Apesar de classicamente o tratamento das peritonites fecais incluir a administração sistêmica de antibióticos, a remoção mecânica dos contaminantes e a restauração da integridade gastrintestinal, ainda se pesquisa o uso de novos antibióti$\cos ^{7}$ e antissépticos ${ }^{8-10}$ usados diretamente na cavidade peritoneal para o tratamento das peritonites .

A ampicilina associada ao sulbactam é um agente antimicrobiano, com atividade bactericida, indicada no tratamento da peritonite secundária, pela sua eficácia contra a maioria das bactérias aeróbicas Gram positivas, negativas e também as anaeróbias. $\mathrm{O}$ sulbactam previne a inativação da ampicilina pelas betalactamases bacterianas, aumentando seu espectro de ação ${ }^{11}$.

Diversos modelos de indução de peritonite foram utilizados para o estudo de estratégias terapêuticas como: a inoculação de suspensão bacteriana conhecida em peritônio livre; a perfuração intestinal experimental; a isquemia de segmento intestinal isolado; a introdução intraperitoneal de suspensão fecal e a inoculação de cápsula gelatinosa contendo suspensão fecal e bacteriana ${ }^{12-14}$.

A peritonite pode ser classificada quanto à origem em: primária, secundária e terciária. $\mathrm{Na}$ primária, também chamada espontânea, não há associação com outras fontes abdominais, secundárias de infecção. A contaminação se dá por via hematogênica, linfática ou pela via transmural. Associada a situações clínicas como: cirrose, tuberculose e as diálises peritoneais $^{15}$. A secundária é a forma mais frequiente, representa a infecção da cavidade peritoneal resultante da perda da integridade anatômica do trato gastrintestinal e pode se manifestar como peritonite aguda, pós-operatória ou traumática $^{16}$. A terciária é definida como processo infeccioso do abdome em que a deficiência dos mecanismos de defesa do paciente e a falta de controle do processo infeccioso determinam uma peritonite difusa persistente ${ }^{15}$.

Estudos microbiológicos do líquido peritoneal em pacientes com peritonite secundária demonstram associação de germes aeróbios e anaeróbios. Essas infecções são geralmente polimicrobianas, sendo a E. coli e o Bacterióides fragilis freqüentemente encontrados ${ }^{17}$.

Os princípios contemporâneos de tratamento da infecção intra-abdominal incluem ressuscitação hemodinâmica, suporte fisiológico ao paciente, administração sistêmica de agentes antimicrobianos contra os patógenos documentados ou prováveis e controle cirúrgico precoce de qualquer fonte de contaminação microbiana com correção dos processos de doenças subjacentes ${ }^{16}$.

Em relação aos procedimentos cirúrgicos a serem realizadas é fundamental a avaliação precisa das indicações de suturas, anastomoses ou estomas. $\mathrm{O}$ fechamento da cavidade deve ser realizado na ausência de infecção grave, restos de necrose e limpeza satisfatória da mesma; drenagem cavitária parece inefi- caz na maioria dos $\operatorname{casos}^{17}$. As peritoneostomias ${ }^{18}$ e a técnica semi-aberta poderão ser utilizadas em casos selecionados; lavagem contínua pós-operatória tem papel controverso. Relaparotomias programadas ou de demanda tem seu papel no tratamento das peritonites, com a indicação cada vez mais freqüente da relaparotomia de demanda, executada quando ocorre piora clínica ou persistência da infecção ${ }^{17}$.

Foram desenvolvidos ao longo das ultimas décadas inúmeros modelos animais que simulam as etapas fisiológicas ocorridas durante a peritonite aguda. Peritonite foi induzida em porcos ${ }^{14}$, ratos ${ }^{19}$, coelhos ${ }^{20}$ e cães ${ }^{21}$. Os modelos utilizados contribuem para aumentar o conhecimento do processo infeccioso peritoneal e prover dados para melhor avaliar a terapêutica em humanos ${ }^{12}$.

Dentre os modelos propostos, alguns evoluem essencialmente com formação de abscessos, enquanto outros são eficazes no desenvolvimento de peritonite bacteriana secundária difusa ${ }^{13,14,22}$.

O modelo de peritonite mais utilizado atualmente inclui a ligadura do cecum. Wichterman et al. ${ }^{23}$, em 1980, propuseram a punção cecal, após ligadura, com propósito de drenar conteúdo fecal na cavidade peritoneal favorecendo o desenvolvimento da peritonite. Outros modelos podem ser citados: inoculação de suspensão bacteriana em peritôneo livre, perfuração intestinal experimental ${ }_{14}^{14}$, ligadura cecal ou apendicular ${ }^{14}$, isquemia de segmento intestinal isolado ${ }_{12}^{1}$ e cápsulas duplas para formação de abscessos cavitários ${ }^{12}$.

Estratégias terapêuticas e complicações cirúrgicas puderam ser avaliadas: uso de fios de sutura e anastomoses intestinais ${ }^{24}$; uso intraperitoneal de anti-sépticos ${ }^{25}$; antibióticos intra-peritoneais ${ }^{26,27}$ lavagem peritoneal mecânica com solução de $\mathrm{NaCl} 0,9 \%$, heparinização ${ }_{32}^{28-31}$, além do uso intra-cavitário de inúmeras substâncias ${ }^{32}$.

A utilização de material fecal como contaminante é de difícil reprodutibilidade. Cápsula de bário e material fecal e esponjas com coliformes são indutoras de abscessos cavitários. A ligadura-punção do cecum foi descrita como indutora de abscessos e de peritonites generalizadas ${ }_{i}$ A ligadura-transfixação proposta inicialmente por Aguiar et al , em 1996, foi eficaz em produzir peritonite generalizada em $100 \%$ dos ratos estudados.

Rosman et al., em 1999, trabalhando com peritonite em ratos referiram redução do crescimento bacteriano, concentração de endotoxinas, formação de abscessos e mortalidade após lavagem peritoneal com adição de imipenem / cilastina $^{33}$.

Reis, em 2001, estudando a aderência peritoneal, observou melhor controle das aderências com o uso intraperitoneal de ampicilina subactam associada ou não ao ácido hialurônico a $0,8 \%$, entretanto, não notou diferença em relação ao índice de culturas bacterianas positivas ${ }^{13}$.

Estudos experimentais tem mostrado diminuição da formação de abscessos e aumento da taxa de sobrevida após uso intraperitoneal ou subcutâneo da heparina ${ }^{34}$. 
A importância do óxido nítrico $(\mathrm{ON})$ na biologia médica foi reconhecida em 1992, quando a mesma passou a ser denominada "molécula do ano".

O ON é um mediador geral na comunicação célula a célula. Proporciona influência vasodilatadora contínua, modificando a função das células circulantes, além de atuar como um neurotransmissor. Trata-se de um complexo instável, capaz de atravessar membranas com grande facilidade ${ }^{36}$. A sua ação na imuno-regulação está presente na inflamação e nos mecanismos de autoimunidade. Esta molécula tem revolucionado e obrigado revisão de paradigmas da medicina, principalmente em neurologia, cardiologia, nefrologia e gastroenterologia ${ }^{37}$.

É produzida a partir do substrato L-arginina pela enzima síntese do óxido nítrico (NOS).

O ON parece estar envolvido em inúmeros mecanismos fisiológicos vasculares, neurológicos e imunitários ${ }^{5}$. Deve estar relacionado com a hipotensão associado ao choque séptico, migração de neutrófilos ${ }^{5}$, patogênese da asma brônquica ${ }^{38} \mathrm{e}$ malária .

Através da ativação da guanilciclase, o ON aumenta os níveis intra-celulares de guanidina-monofosfato cíclico (GMP-cíclico), causando redução de cálcio intracelular. Tal fenômeno é responsável por relaxamento de células musculares lisas tanto no sistema vascular como em outros tecidos (músculo liso e intestinal), inibição de aderência e agregação plaquetária e inibição da quimiotaxia de neutró

Existem evidências indiretas de aumento da sobrevida em modelos experimentais de choque séptico com a utilização de inibidores da síntese de ON, entretanto, com aplicação que não superou a fase experimental ${ }^{36}$.

\section{Procedimentos}

A utilização de antibióticos associados ao líquido de irrigação peritoneal, tem resultados controversos. A ampicilina-subactam é uma associação relativamente nova. Em nosso meio, foi encontrado apenas um estudo avaliando o uso intraperitoneal terapêutico desse antibiótico na peritonite induzida em modelo animal ${ }^{13}$, levando em consideração a prevenção de aderências peritoneais. A inexistência de estudo avaliando dosagem plasmática de óxido nítrico e resposta inflamatória na peritonite em ratos, motivou a realização deste estudo.

O estudo teve por objetivo avaliar as variações nos níveis plasmáticos do óxido nítrico, bem como a contagem de eosinófilos, linfócitos, monócitos e neutrófilos no sangue e no lavado peritoneal em ratos com peritonite, após o uso terapêutico, intraperitoneal da ampicilina associada ao sulbactam.

\section{Métodos}

\section{Casuística}

Foram utilizados 24 ratos Wistar adultos, machos, procedentes do biotério de Biofísica e aclimatados no Núcleo de Cirurgia Experimental (NCE) do Hospital das Clínicas da Universidade Federal de Pernambuco (HC-UFPE). Os animais receberam água "Ad libitum" e alimentação padrão tipo Labina ${ }^{\circledR}$ até o início dos experimentos.

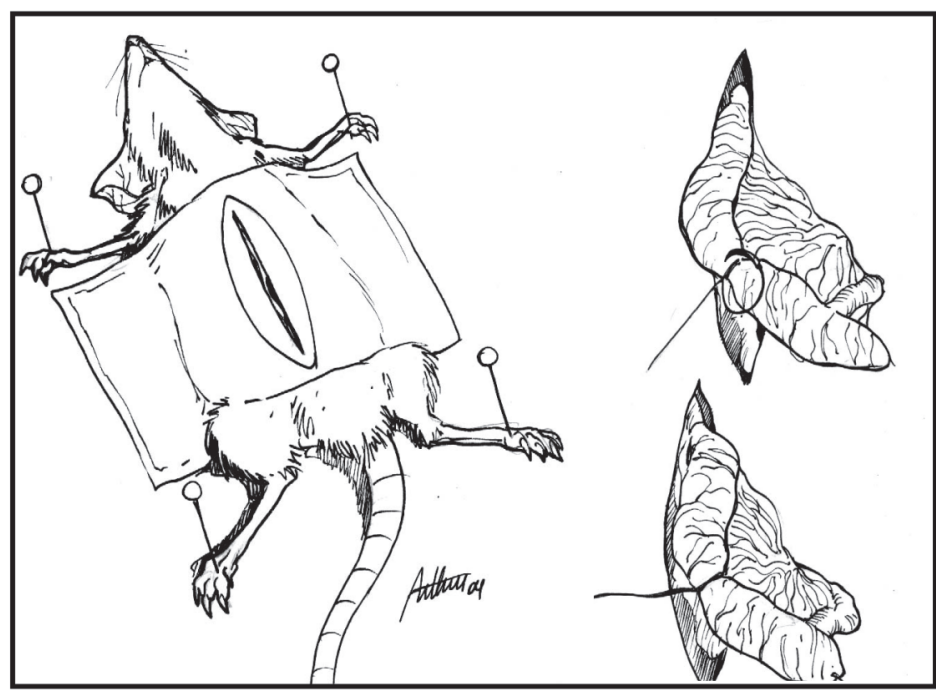

FIGURA 1 - Técnica da indução da peritonite secundária em ratos 
Realizada indução de peritonite secundária seguindo modificação técnica do modelo idealizado por Aguiar et al ${ }^{1}$, sendo procedida à ligadura do cecum $0,5 \mathrm{~cm}$ acima da válvula íleocecal seguida de transfixação com a própria agulha, exteriorizando o fio 3,0 cm além da parede do cecum. Síntese realizada em 2 planos de sutura contínua com Polipropileno 3,0 (Figura. 1). Os ratos receberam rehidratação com $10 \mathrm{ml}$ de soro Ringer com lactato administrado por via subcutânea, seguida da aplicação de $30 \mathrm{mg}$ de ampicilina/sulbactam por via intramuscular (IM) nos 18 ratos.

Em caso de óbito per-operatório, o mesmo seria substituído, de acordo com o seu grupo de estudo.

Realizada 24 horas após o procedimento inicial, sendo realizada soltura do fio de seda, com restabelecimento de trânsito intestinal. Naquele momento os 18 ratos foram divididos em três grupos: Grupo A: lavagem com solução fisiológica 0,9 $(5 \mathrm{ml})$ e enxugamento com duas gazes estéris + soro fisiológico 0,9\% - 8ml; Grupo B (estudo): lavagem com solução fisiológica $0,9(5 \mathrm{ml})$ e enxugamento com duas gazes estéris + soro fisiológico 0,9 em mesmo volume com 30mg de ampicilina associada ao sulbactam (UNASYN - Pfizer - Brasil); Grupo C: soltura da ligadura-transfixação, apenas; após re-síntese com mesma técnica e fio, ministrados $10 \mathrm{ml}$ subcutâneo de Ringer lactato e aplicação de 30mg IM de ampicilina/sulbactam em todos os 18 ratos; Grupo D (controle negativo): foram utilizados seis ratos para coleta do lavado peritoneal e coleta de sangue para contagem.

Realizada 24 horas após re-laparotomia com a finalidade de coletar material para análise através da colocação de $10 \mathrm{~mL}$ de solução fisiológica que permaneceu 1 minuto misturada às secreções peritoneais. Sendo coletados $4 \mathrm{~mL}$ para estudo. Foram confeccionadas lâminas a partir do lavado peritoneal para contagem total e diferencial de leucócitos (fig. 2). A amostra de sangue colhida serviu para preparação de lâminas para leucometria (fig. 4). No pós-operatório os ratos permaneceram em gaiolas individuais com fornecimento livre de água e ração, logo após recuperação anestésica.

Após finalização dos procedimentos de coleta, induzido óbito através de dose letal de ketamina. Os animais foram acondicionados em recipientes adequados, congelados e coletados pelo Serviço Municipal de Lixo de Biotério.

$\mathrm{Na}$ análise estatística foi aplicado o teste Bonferroni para comparações múltiplas. Os resultados das variáveis quantitativas foram expressos por suas médias e respectivos desvios padrão. $\mathrm{O}$ nível de significância estabelecido para a análise foi de 0,05 .

Todos os cálculos foram realizados pelo programa SPSS versão 11.0 (Statistical Package for Social Sciences).

\section{Resultados}

\section{Dosagem de óxido nítrico}

As médias das dosagens plasmáticas de óxido nítrico e respectivos desvios-padrão foram: grupo $\mathrm{A}-19,6 \pm 9,5$; grupo $\mathrm{B}$ $16,7 \pm 5,1$; grupo C $13,1 \pm 7,3$ e grupo D $31,5 \pm 9,7$. Representados em $\mu \mathrm{m}$ de nitrito /nitrato.

TABELA 1 - Dosagem de ON

\begin{tabular}{lccccc}
\hline & N & Mínimo & Maximo & Média & Desvio Padrão \\
\hline Grupo A & 6 & 7,9 & 31,7 & 19,583 & 9,4730 \\
Grupo B & 6 & 8,9 & 23,3 & 16,717 & 5,1254 \\
Grupo C & 6 & 6,6 & 27,5 & 13,067 & 7,3489 \\
Grupo D & 7 & 21 & 46 & 31,54 & 9,712 \\
\hline
\end{tabular}


TABELA 2 - Leitura das lâminas do sangue

\begin{tabular}{|c|c|c|c|c|c|}
\hline & $\mathbf{N}$ & Mínimo & Maximo & Média & Desvio Padrão \\
\hline \multicolumn{6}{|l|}{ Grupo A } \\
\hline Basófilo & 6 & 0 & 0 & 0,00 & 0,000 \\
\hline Eosófilo & 6 & 3 & 7 & 4,33 & 1,751 \\
\hline Linfócito & 6 & 0 & 0 & 0,00 & 0,000 \\
\hline Linfócito $t$ & 6 & 27 & 56 & 39,50 & 10,635 \\
\hline Monócito & 6 & 4 & 8 & 6,33 & 1,862 \\
\hline Neutrófilo & 6 & 29 & 63 & 49,67 & 12,111 \\
\hline \multicolumn{6}{|l|}{ Grupo B } \\
\hline Basófilo & 6 & 0 & 0 & 0,00 & 0,000 \\
\hline Eosófilo & 6 & 2 & 6 & 4,00 & 1,414 \\
\hline Linfócito & 6 & 0 & 0 & 0,00 & 0,000 \\
\hline Linfócito $t$ & 6 & 29 & 53 & 45,00 & 8,485 \\
\hline Monócito & 6 & 2 & 10 & 6,67 & 3,077 \\
\hline Neutrófilo & 6 & 35 & 62 & 44,00 & 9,879 \\
\hline \multicolumn{6}{|l|}{ Grupo C } \\
\hline Basófilo & 6 & 0 & 0 & 0,00 & 0,000 \\
\hline Eosófilo & 6 & 1 & 4 & 2,83 & 1,169 \\
\hline Linfócito & 6 & 0 & 0 & 0,00 & 0,000 \\
\hline Linfócito $\mathrm{t}$ & 6 & 25 & 61 & 51,33 & 13,574 \\
\hline Monócito & 6 & 3 & 7 & 4,67 & 1,633 \\
\hline Neutrófilo & 6 & 31 & 66 & 41,00 & 12,696 \\
\hline \multicolumn{6}{|l|}{ Grupo D } \\
\hline Basófilo & 6 & 0 & 1 & 0,33 & 0,516 \\
\hline Eosófilo & 6 & 0 & 4 & 1,83 & 1,472 \\
\hline Linfócito & 6 & 0 & 0 & 0,00 & 0,000 \\
\hline Linfócito $\mathrm{t}$ & 6 & 57 & 82 & 69,83 & 8,750 \\
\hline Monócito & 6 & 0 & 7 & 2,17 & 2,787 \\
\hline Neutrófilo & 6 & 17 & 37 & 25,83 & 6,494 \\
\hline
\end{tabular}

Contagem de lâminas no lavado

TABELA 3 - Leitura das lâminas do lavado - Resumo estatístico

\begin{tabular}{lccccc}
\hline & N & Mínimo & Maximo & Média & Desvio Padrão \\
\hline Grupo A & 6 & & & & \\
Linfócito & 6 & 21 & 30 & 26,33 & 1,602 \\
Monócito & 6 & 35 & 68 & 45,17 & 3,386 \\
Neutrófilo & 6 & 8 & 38 & 27,67 & 11,703 \\
Eosófilo & & & & & 10,289 \\
Grupo B & 6 & 23 & 38 & 30,17 & 5,707 \\
Eosófilo & 6 & 0 & 2 & 0,50 & 0,837 \\
Linfócito & 6 & 21 & 36 & 30,00 & 6,450 \\
Monócito & 6 & 24 & 47 & 39,33 & 8,383 \\
Neutrófilo & & & & & \\
Grupo C & 6 & 17 & 31 & 25,67 & 4,803 \\
Eosófilo & 6 & 0 & 9 & 2,67 & 3,670 \\
Linfócito & 6 & 21 & 50 & 30,17 & 11,496 \\
Monócito & 6 & 14 & 62 & 41,50 & 16,682 \\
Neutrófilo & & & & & \\
Grupo D & 6 & 1 & 3 & 1,50 & 0,837 \\
Eosófilo & 6 & 0 & 14 & 6,50 & 4,930 \\
Linfócito & 6 & 83 & 98 & 92,17 & 5,037 \\
Monócito & 6 & 0 & 3 & 1,50 & 1,049 \\
Neutrófilo & & & & & \\
\hline
\end{tabular}




\section{Discussão}

A utilização de modelos experimentais de peritonite tem importância pela dificuldade na realização de estudos clínicos que avaliem condutas terapêuticas em função de limitações éticas e da incapacidade de formação de grupos de estudo homogêneos.

Dentre os diversos modelos desenvolvidos para reproduzir as etapas encontradas na peritonite, há alguns que tendem a gerar abscessos intra-peritoneais localizados e outros processos generalizados ${ }^{1}$.

No presente estudo, o modelo de ligadura transfixação de Aguiar et $\mathrm{al}^{1}$, modificado por Reis ${ }^{22}$ gerou peritonite difusa em $100 \%$ dos casos.

Outros fatores importantes a serem considerados são: o índice de mortalidade e o tempo de sobrevida após instalada a peritonite e sepse a fim de otimizar a observação de determinados eventos mais tardios. O modelo de Aguiar ${ }^{1}$ levava os animais a óbito em até 48 horas, por necrose do cecum. A modificação idealizada por Reis aumentou para mais de sete dias a sobrevida dos animais ${ }^{22}$. A referida modificação consistiu na diminuição do tempo de ligadura do cecum de 48 para 24 horas, permitindo assim a preservação da vitalidade do órgão. A ligadura passou a ser realizada acima da válvula íleo-cecal, provocando obstrução intestinal verdadeira. Os demais itens da técnica original foram mantidos.

O modelo adotado se mostrou eficaz em provocar peritonite generalizada, reconhecida pelo aspecto macroscópico à abertura da cavidade e evidenciada pela mudança no padrão leucocitário encontrado no lavado. No controle negativo é notada a predominância de linfócitos e após indução de peritonite o lavado demonstra aumento importante de neutrófilos.

Dentre os animais submetidos a esse modelo, não foi constatado óbito, fato não notado em estudo piloto prévio, talvez pela ausência da antibioticoterapia intramuscular e hidratação subcutânea. O uso do antibiótico intramuscular nos modelos de peritonite foi valorizado por Reijnem et $\mathrm{al}^{19}$, e reafirmado por Reis ${ }^{22}$. Rosman et al, enfatizaram a importância da hidratação subcutânea nesses modelos ${ }^{34}$.

A escolha do antibiótico decorreu de sua atividade bactericida, da comprovada eficácia contra a flora provável presente no trato gastrintestinal e da menor capacidade indutora de blactamases, menor que a das cefalosporinas ${ }^{22}$. O sulbactam previne a inativação da ampicilina pelas b-lactamases bacterianas, aumentando seu espectro de ação .

A dosagem de ON foi realizada através do reativo de griesse, técnica clássica referida por alguns autores ${ }^{36,39}$.

Estudos com ratos têm sido muito utilizado em modelos de peritonite. Os autores referem baixo custo, alta reprodutibilidade e facilidade de obtenção das cobaias ${ }^{12,40}$.
$\mathrm{Na}$ avaliação da sobrevida durante o tempo decorrido do estudo não houve óbito dentre os animais.Este dado provavelmente está relacionado com adequada hidratação, antibióticos administrados, técnica cirúrgica e período de observação.

Na sepse abdominal foi encontrado um aumento dos níveis de ON por vários autores ${ }^{5,41}$, bem como um aumento na sobrevida em modelos experimentais com a utilização de inibidores da síntese de $\mathrm{ON}^{36}$.

Não houve diferença estatística entre o grupo B (estudo) e os grupos $\mathrm{A} e \mathrm{C}$, em relação à dosagem plasmática de $\mathrm{ON}$. Evans et al., em 1993, encontraram aumento significante nos níveis de nitrato em pacientes sépticos comparados a pacientes normais ${ }^{42}$. Tagan et al., em 1998, relataram um valor preditivo de $100 \%$ para a origem séptica do choque quando o nível de $\mathrm{ON}$ foi superior a $100 \mathrm{mmoL} / \mathrm{L}^{41}$. Esses autores enfatizam o valor da dosagem de ON na diferenciação entre o choque séptico e cardiogênico ${ }^{41}$. As discrepâncias entre os níveis plasmáticos de ON comparando diversos trabalhos tem razões pouco claras, ocorrendo uma tendência a níveis muito mais baixos em modelos experimentais de peritonite que após injeção de LPS, porém semelhantes aos níveis plasmáticos em pacientes sépticos 5 .

No controle normal o nível de ON foi 31,4mmoL/L, achado semelhante ao descrito por Tagan et al ${ }^{41}$, os níveis de ON nos grupos A, B e C foram menores que os achados de Le Roy et al., que variaram de 50 a $150 \mathrm{mmol} / 1$, após 24 horas de infecção . O uso de antibióticos parenterais e a forma de indução de peritonite podem estar relacionados com essas diferenças.

O nível de ON no grupo $\mathrm{D}$ (controle normal) foi maior que nos grupos A, B e C, inclusive alcançando diferença estatisticamente significante entre os grupos B e D. Talvez o momento da coleta e o uso da ampicilina/sulbactam tenham influenciado este achado. A dosagem de ON foi realizada nos grupos A, B e C após 24 horas do tratamento da infecção, como descrito por Le Roy et al ${ }^{5}$. Consenso Brasileiro de Sepse ${ }^{43}$ não descreve o ON como marcador específico. Tagan et al ${ }^{41}$ referem correlação entre intensidade do quadro séptico e nível plasmático de $\mathrm{ON}$.

Quando foi comparado o número de eosinófilos, linfócitos, monócitos e neutrófilos, não houve diferença estatisticamente significante entre os grupos A, B e C.

Friedman et $\mathrm{al}^{43}$ referem que a leucocitose não é marcador específico ou sensível de infecção, bem como, o valor limitado do desvio à esquerda, que reflete a formação de formas jovens pela medula óssea. Contudo, assim como mudanças na temperatura corporal, esses parâmetros são facilmente mensuráveis e continuam fundamentais na monitorização da sepse $^{43}$.

Em relação à contagem diferencial não houve diferença estatisticamente significativa considerando eosinófilos, 
neutrófilos, linfócitos ou monócitos. O tratamento antibiótico e o tempo de coleta após 24 horas pode não ter caracterizado estas diferenças.

Notada a inexistência de diferenças estatisticamente significantes, entre os grupos A, B e C, em relação a contagem de eosinófilos, linfócitos, monócitos e neutrofílos no lavado peritoneal. O número de eosinófilos foi significantemente maior nos grupos A, B e C, em relação ao grupo D.Talvez o material de sutura utilizado nos grupos A, B e $\mathrm{C}$, e uma reação tipo alérgica poderiam estar relacionados com tal achado. Houve uma tendência a um menor número de neutrófilos no lavado no grupo $\mathrm{C}$ (soltura da ligadura), em relação ao grupo A, denotando uma migração de neutrófilos mais adequada no grupo onde houve lavagem cavitária com solução salina, em relação ao grupo onde houve apenas soltura da ligadura cecal. Torres et al., em modelo de peritonite em ratos, evidenciou diminuição da mortalidade após lavagem cavitária com solução fisiológica comparada a simples limpeza da cavidade com compressas de gases ${ }^{44}$. A chegada dos neutrófilos ao local da inflamação/infecção (peritônio) tem importância para a defesa do organismo pela ocorrência da fagocitose dos microorganismos, levando-os à morte por produção de várias substâncias bacteriostáticas e tóxicas ${ }^{45}$.

O papel dos antibióticos utilizados por via intraperitoneal continua controverso. Alguns autores defendem o seu uso por encontrarem melhor controle de aderências pós-operatórias $^{22}$, redução de mortalidade ${ }^{7,8}$, redução de endotoxinas e formação de abscessos ${ }^{33}$. Outros autores não encontraram diferença após utilização tópica de antibióticos em relação à mortalidade ${ }^{26}$ inclusive enfatizando o risco do uso em alguns pacientes $^{46}$.

O uso de agentes não antimicrobianos como: heparinas, dextrans, PVPI, entre outros tem resultados conflitantes além de alguns relatos de complicações relacionadas a seu uso ${ }^{22,47}$.

Neste estudo, não foi encontrado diferença significativa em relação aos níveis de $\mathrm{ON}$, leucometria ou migração de neutrófilos no líquido peritoneal com o uso de ampicilina/ sulbactam intracavitária, ressaltando apenas uma tendência a uma maior migração de neutrófilos nos grupos submetidos à lavagem cavitária com solução fisiológica em relação ao grupo C (soltura da ligadura), porém sem alcançar significação estatística.

Pelo caráter controverso do uso tópico de substâncias antimicrobianas e não-antimicrobianas para o tratamento das peritonites secundárias, torna-se clara a necessidade de estudos controlados para avaliação de seu uso.

\section{Conclusões}

Considerando-se a metodologia empregada e o número de animais estudados, com base nos resultados do presente estudo, pode-se concluir, com probabilidade de acerto superior a 95\%, que: A utilização de ampicilina associada a sulbactam por via intraperitoneal em ratos com peritonite fecal: não alterou os níveis plasmáticos de óxido nítrico; não alterou a contagem de eosinófilos, linfócitos, monócitos e neutrófilos tanto no sangue como no lavado peritoneal.

\section{Referências}

1. Aguiar JLA, Moreira IEG, Chaves MM, Lopes SL, Santana V. Peritonite experimental: Modificação técnica do modelo de ligadura do ceco em ratos. An Fac Med Univ Fed Pernamb 1996; 41: 59-62.

2. Ferraz, AAB, Ferraz EM. Sepse Abdominal Programa de Atualização de Antibióticos em Cirurgia. 2002; 3:1-25.

3. Böhlke M. Imunossupressão induzida pela malária: existe um papel para o óxido nítrico? Rev Bras Alerg Imunopatol 1999; 22 : 173-78.

4. Le Roy D, Heumann D, Glause MP, Mauël J, Smith J, Corradin. Nitric oxide production in experimental gram-negative infection: studies with citokine receptor-deficient mice. Shock 1998; 10: 37-42.

5. Ferraz EM, Ferraz AAB. Síndrome da resposta inflamatória sistêmica. In: Ferraz AAB, Mathias CAC, Ferraz EM. Condutas em cirurgia geral. $1^{\mathrm{a}}$ ed. Rio de Janeiro: Medsi; 2003; 6: 78-95.

6. Janeway Jr C, Travers P, editores. Imunobiologia. O sistema imunológico na saúde e na doença. $2^{\text {a }}$ ed. São Paulo: Artes Médicas Sul Ltda. 1996.

7. Perdue PW, Kazarian KK, Nevola J, Law WR, Williams T. The use of local and systemic antibiotic in rat fecal peritonitis. J Surg Res 1994; 57: 360-65.

8. Ablan CJ, Olen RN, Dobrin PB,ÒKeefe P, Tatarowicz W, Freeark RJ.Eficacy of intraperitoneal antibiotics in treatment of severe fecal peritonitis.Am J Surg 1991;162:453-6.

9. Vallance S, Waldron R. Antiseptic vs. saline lavage in purulent and faecal peritonitis. J Hosp Infect 1985; 6: 87-91.

10. Platt J, Jones RA, Bucknall RA.Intraperitoneal antiseptics in experimental bacterial peritonitis.Br J Surg 1984; 71:626-8.

11. Walker AP, Nichols RL, Wilson RF, Bivens BA, Trunkey DD, Edmiston Jr CE, Smith JW, Condon RE. Efficacy of a b-lactamase inhibitor combination for serious intra-abdominal infections. Ann Surg 1993; 217: 115-121.

12. Albuquerque PC. Infecção Peritoneal Enterocócica: Modelo Experimental em Ratos Imunossuprimidos.Tese, Mestrado, p.14, UFPE, Recife, 1991.

13. Reis TSCC. Ácido hialurônico e ampicilina associada ao sulbactam na prevenção de aderências peritoneais estudo em modelo de peritonite bacteriana em ratos. [Tese de Mestrado em Cirurgia] Universidade Federal de Pernambuco. Recife. 2001.

14. Browne MK, Leslie GB. Animal models of peritonitis. Surg Gynecol Obstet 1976; 143: 738-42.

15. Ferraz EM, Ferraz AAB. Síndrome da resposta inflamatória sistêmica. In: Ferraz AAB, Mathias CAC, Ferraz EM. Condutas em cirurgia geral. $1^{\text {a }}$ ed. Rio de Janeiro: Medsi; 2003; 59: 629-636. 16. Felac. Infecção Intrabdominal. In: Herida e infección quirúrgica. 2001; 6: 397-416. 
17. Fahel E. Peritonite secundária. In: Fahel E, Amaral P, Azaro E. Manual de Atualização em Cirurgia Geral - Diagnóstico e Tratamento. $1^{\text {a }}$ ed. Rio de Janeiro: Revinter. 2001; 12: 165-74.

18. Pagnossin G. Laparostomia na infecção intra-abdominal - Análise de 46 pacientes. [Tese de Mestrado em Cirurgia]. Universidade Federal de Pernambuco. Recife, 1995.

19. Reijnen MMPJ, Meis JFGM, Postma VA, van Goor H. Prevention of intra-abdominal abscesses and adhesions using a hyaluronic acid solution in a rat peritonitis model. Ar Surg 1999; 134: 997-01.

20. Simopoulos C, Kouskoukis C, Polychronides A, Bezirtzoglou E. Effect of different combinations of antibiotics on experimental septic peritonitis in rabbits. J Clin Lab Res 1994; 24: 167-170.

21. Hau T, Payne WD, Simmons RL. Fibrinolytic activity of the peritoneum during experimental peritonitis. Surg Gynecol Obstet 1979; 148: 415-18.

22. Reis TC, Aguiar JLA, Lacerda CM, Brandt CT. Modelo de peritonite secundária em ratos. An Fac Med Univ Fed Pernamb 2001; 46: 115-18

23. Wichterman KA, Baue AE, Chaudry IH. Sepsis and septic shocka review of laboratory models and a proposal. J Surg Res 1980; 29: 189-201.

24. Gonçalves RM, Esquerdo CRM, Petroianu A, Barbosa AJA. Influência de aderências peritoneais e fio cirúrgico na tensão de ruptura da parede abdominal em ratos. Rev Col Bras Cirur 2000; 27: $147-52$

25. Schein M, Saadia R, Decker G. Intraoperative peritoneal lavage. Surg Gynecol Obstet 1988; 187-95.

26. Lally BKP, Shorr LD, Nichols RL. Aminoglycoside peritoneal lavage: lack of efficacy in experimental fecal peritonitis. J Ped Surg 1985; 20: 541-42.

27. Rappaport WD, Holcomb M, Valente J, Chvapil M. Antibiotic irrigation and the formation of intraabdominal adhesions. Am J Surg 1989; 158: 435-37.

28. Rocha JJR, Aprilli F, Santos Jr JCM, Guimarães AS. Tratamento da peritonite generalizada grave: Trabalho experimental em cobaias. Rev Col Bras Cirur 1986; 13: 218-23.

29. Chalkiadakis G, Kostakis A, Karayannacos PE, Giamarellou H, Dontas I, Sakellariou I, Skalkeas GD. The effects of heparin upon fibrinopurulent peritonitis in rats. Surg Gynecol Obstet 1983; 157: 257-60.

30. Vela AR, Littleton JC, O'Leary JP. The effects of minidose heparin and low molecular weight heparin on peritonitis in the rat. Am Surg 1999; 5: 473-75.

31. Davidson RK, Cardenas A, Busuttil RW. The effects of heparin and low molecular weight dextran on survival after fibrinopurelent peritonitis. Surg Gynecol Obstet. 1981; 153: 327-31.

32. Leiboff AR, Soroff HS. The treatment of generalized peritonitis by closed postoperative peritoneal lavage: A critical review of the literature. Arch Surg 1987; 122: 1005-10.
33. Rosman C, Westerveld GJ, Kool K, Bleichrodt RP. Local treatment of generalised peritonitis in rats; effects on bacteria, endotoxin and mortality. Eur J Surg 1999; 165: 1072-79.

34. Vela AR, Littleton JC, O'leary JP. The effects of minidose heparin and low molecular weight heparin on peritonistis in the rat. Am Surg 1999; 5: 473-477.

35. Lemos FN. Infecção em cirurgia: Biologia da infecção. In: Ferraz AAB, Lima FEBA, Lima EMC, Lima MA, Bacelar LS, Aguiar JLA, Ferreira Filho HA, Ferraz EM. Bases da técnica cirúrgica e da anestesia. $1^{\text {a }}$ ed. Recife: Editora Universitária 2001; 47: 247-281.

36. Arzate-Villafaña JA, López CV. Inhibición de la síntese del óxido nítrico. Papel en la sobreviva y hemodinamia de un modelo experimental de peritonitis fecal. Rev Sanid Milit Mex 1998; 52: 257-63.

37. Flora Filho R., Zilbers.tein B. Óxido nítrico: o simples mensageiro percorrendo a complexidade. Metabolismo, síntese e funções. Rev. Assoc. Med. Bras. 2000; 46: 1-8.

38. Teles Filho PA. Asma brönquica: Resposta tardia da asma. [serial online] 2004. Disponível em URL:http://www.asmabronquica.com.br.

39. Yang CW, Hwang TL, Wu CH, Lai PC, Huang JY, Yu CC, Shyr $\mathrm{MH}$, Huang CC. Peritoneal nitric oxide is a marker of peritonitis in patients on continuous ambulatory peritoneal dialysis. Nephrol Dial Transplant. 1996; 11:2466-71.

40. Carvalho GL. Choque endotoxêmico em coelhos: Importância da interleucina-8. [Tese de Mestrado em Cirurgia] Universidade Federal de Pernambuco. Recife. 1996.

41. Tagan D, Eckert P, Markert M, Feihl F, Schaller MD. Blood nitrate levels in septic and cardiogenic schock. Clin Int Care 1998; 9: 71-76.

42. Evans T, Carpenter A, Kinderman H, Cohen J. Evidence of increased nitric oxide production in patients with the sepsis syndrome. Circ Shock 1993; 41: 77-81.

43. Friedman G, Lobo S, Rigato O. Consenso Brasileiro de Sepse. Diagnóstico, monitorização da resposta inflamatória.

44. Torres OJM, Macedo EL, Melo TCM, Costa JVG, Nunes PMS, Viana RMM, Dietz UA. Fecal peritonitis in rats: efficacy of the peritoneal lavage with saline solution. Acta Cir Bras [serial online] 1999 Apr Jun; 14(2). Available from: URL: http://www.scielo.br/acb.

45. Silva WTF. Aspectos da resposta inflamatória em ratos adultos endotoxêmicos submetidos à desnutrição no período de aleitamento. [Tese de Mestrado em Nutrição]. Universidade Federal de Pernambuco, Recife. 2002.

46. Ericsson CD, Duke JH, Pickering LK. Clinical pharmacology of intravenous and intraperitoneal aminoglycoside antibiotics in the prevention of wound infections. Ann Surg 1978; 188: 66-70.

47. Sun Y, Williams CH, Hardaway RM, Shen J. The effect of heparinization on intra-abdominal infection and acute pulmonary failure. Int Surg 1997; 82: 367-70. 
Kreimer F, Aguiar JLA, Castro CMMB, Lacerda CM, Reis T, Lisboa Júnior F. Therapeutical and inflammatory response in rats with secondary peritonitis and topical use of ampicilin/sulbactam. Acta Cir Bras [serial on line] Available from: URL: htt://www.scielo.br/ acb.

ABSTRACT - Objectives: The acute peritonitis is an important cause of sepsis and death on intensive care units and surgery. The treatment must include: systemical use of antibiotics, drainage of abscess and restauration of gastrointestinal integrity. The topical use of antibiotics in the peritoneal cavity is controversial. The aim of this study was to evaluate the use of topical use of ampicilin/ sulbactam in the treatment of peritonitis. Methods: We measured the plasmatic levels of nitric oxide, count of eosinophils, lymphocytes, monocytes, and neutrophils in blood and peritoneal cavity, using a model of peritonitis in rats (transfixation and ligature of cecum). Twenty four Wistar rats were divided in 4 groups ( $\mathrm{n}=6$ each). group A: induction of peritonitis with ligature of cecum and topical treatment with saline; group B: induction of peritonitis with ligature of cecum and topical treatment with ampicilin/sulbactam; group C: transfixation of cecum; group D: laparotomy and peritoneal exsudate + blood sample. The transfixation-ligture of cecum remained for $24 \mathrm{hs}$ before treatment. A relaparotomy was performed in 18 rats and peritoneal exsudate/blood were collected. Dosage of Nitric oxide, count of eosinophil, lynphocytes, monocytes, and neutrophils in blood and peritoneal exsudte were done. Results: The difference was not significant in the levels of nitric oxide, eosinophil, lynphocytes, monocytes, and neutrophils in blood and peritoneal exsudate $(p>0,05)$ among the studied groups. Conclusion: The use of ampicilin associated to sulbactam via intraperitoneal in rats with fecal peritonitis did not change survival.; the levels of plama nitric oxide, count of eosinophil, lynphocytes, monocytes, and neutrophils in blood and peritoneal exsudate were not affected.

DESCRITORES: Peritonite. Antibióticos. Ratos.

Correspondência:

Rua Jacobina, 45/1902

Graças, Recife, PE 